\title{
Characterisation of surface martensite-austenite transformation during finish turning of an AISI S15500 stainless steel
}

\author{
Alexandre Mondelin
}

\author{
Université de Lyon, \\ ENISE, LTDS, UMR CNRS 5513, \\ 58 Rue Jean Parot, 42023 Saint-Etienne, France and \\ Université de Lyon, \\ INSA, LaMCoS, UMR CNRS 5259, \\ 27 Avenue Jean Capelle, 69621 Villeurbanne, France \\ E-mail: alexandre.mondelin@enise.fr
}

\section{Joël Rech and Eric Feulvarch Université de Lyon, ENISE, LTDS, UMR CNRS 5513, \\ 58 Rue Jean Parot, 42023 Saint-Etienne, France \\ E-mail: joel.rech@enise.fr \\ E-mail: Eric.feulvarch@enise.fr}

Michel Coret

\author{
École Centrale de Nantes, \\ GeM, UMR CNRS 6183, \\ 1 rue de la Noë BP 92101, 44321 Nantes cedex 3, France \\ E-mail: michel.coret@ec-nantes.fr
}

\begin{abstract}
During machining, extreme temperature conditions appear in the cutting zone (from 700 to $1,000^{\circ} \mathrm{C}$ with heating rates around $10^{6}{ }^{\circ} \mathrm{C} / \mathrm{s}$ ). Consequently, the metallurgical models used to simulate the impact of the manufacturing process must be adapted to this fast thermal kinetics. Stress-free dilatometry tests have been performed to determine the austenisation kinetics of an AISI S15500 martensitic stainless steel and to identify a phenomenological model. Experimental heating rates vary from $6{ }^{\circ} \mathrm{C} / \mathrm{s}$ to $11,000{ }^{\circ} \mathrm{C} / \mathrm{s}$. The metallurgical model calibrated for high heating rates, has been applied to a typical machining thermal cycle. It has been shown that martensite $\rightarrow$ austenite transformation does not have the time to significantly occur during the finish turning of AISI S15500 under standard cutting conditions. This result has been confirmed using retained austenite measurements in the machined surface layer.
\end{abstract}

Keywords: dilatometry; martensite-austenite transformation; high heating rate; turning; metallurgical model; surface integrity.

\section{Introduction}

Precipitated hardening (PH) stainless steels (like an AISI S15500 steel) show excellent mechanical properties, low distortion, excellent weldability and good corrosion resistance. That is why they are used in the aerospace and nuclear industries. Moreover, predicting the fatigue resistance of mechanical parts is crucial to these industries. Several studies (like Liu and Yang, 2001) have shown that fatigue resistance is directly and significantly influenced by several parameters such as surface roughness (Smith et al., 2007), residual stress (Yang et al., 2002) and microstructure (Bissey-Breton et al., 2007), which are commonly summarised by the term 'surface integrity' (Davim, 2008). The influence of surface integrity on the functional performance and lifetime of machined 
components has been widely discussed in the literature (Jawahir et al., 2011). Surface integrity depends on the thermo-mechanical loadings induced by all previous manufacturing operations, even if the final operation has a major responsibility (Rech et al., 2008). Among the finishing operations applied to critical parts, longitudinal finish turning is widely used. Moreover, the influence of the surface integrity and the effects of microstructure changes on residual stresses in the machined part are really significant and cannot be overlooked (Davim, 2008), especially when the trend is to machine stainless steel using high speed turning (Fernández-Abia et al., 2012).

This strong relationship between surface integrity and fatigue resistance leads to a need for predictive models of microstructure changes and residual stress levels. Currently in the literature, most models only focus on residual stress prediction (Valiorgue et al., 2012). The effects of microstructure changes are not taken into account (Outeiro et al., 2008). On the other hand, some studies try to consider phase transformation during machining in order to predict the final surface integrity (and especially surface layers). Different approaches and models are used. Aramcharoen and Mativenga (2008), who works on hard turning impact on tempered steels, provides a good overview of different studies and explanations for white layer formation. For example, Chou and Song (2005) worked on the surface layer predictions in the finish hard turning of AISI52100 steel (60-62 HRc). An analytical thermal model is used to obtain the final temperature distributions due to the overall heat sources. Chou and Song (2005) assume that the white layer in steel machining is the phase transformation (austenitisation) product. So, the metallurgical model is only based on one phase transformation temperature $\left(727^{\circ} \mathrm{C}\right.$, which is the austenitisation transformation temperature of steel in equilibrium conditions). The penetration depth of austenitising temperature is used to estimate the white layer depth. The thermal kinetic influence is not taken into account.

A comparable study on the hard-turning of AISI52100 is presented by Umbrello and Filice (2009). This paper presents an experimental and numerical approach to improve the surface integrity by incorporating the white and dark layer formation. The phase transformation criteria are based on hardness modification and on an austenite-start temperature. The austenite-start temperature ranges from $550^{\circ} \mathrm{C}$ to $650^{\circ} \mathrm{C}$ (depending of the initial material hardness but not on the heating rate).

Ramesh and Melkote (2008) suggested using the Clausius-Clayperon equation to account for the effect of pressure (stress) on the austenite start temperature. AISI 52100 steel yields a final $\alpha^{\prime}-\gamma$ transformation temperature of $614^{\circ} \mathrm{C}$. In the numerical machining model, if the temperature of a material point being analysed exceeds the austenite start temperature, it is assumed to be instantaneously austenitised. Only two austenitisation levels are considered: $0 \%$ and $100 \%$ of austenite.

This state-of-art survey highlights the difficulty of current studies to calibrate a metallurgical model adapted to the high thermal kinetics of machining. The temporal aspect of the martensite to austenite transformation is often neglected. A simple austenitisation start temperature is often used. This approach is only valid in the equilibrium condition of temperature (or for very low heating rates such as $60^{\circ} \mathrm{C} /$ hour (Constant et al., 1992). That is clearly not the case during a machining operation. The transitional step of the $\alpha^{\prime} \rightarrow \gamma$ transformation is not considered and models are only able to make predictions if autenitisation occurs or not (two transformation levels).

Martensite to austenite transformation occurs with a diffusional process (Constant et al., 1992). It means a move of carbon atoms along distances higher than the elementary 
size of the crystal structure. The result is that austenitisation is not instantaneous and very dependent on thermal kinetics (Figure 1, Brosse, 2009). Finally, a metallurgical transformation model used in machining simulation should be able to predict the proportion of initial and produced phases during the machining process. The model should inevitably integrate the thermal kinetics (heating and cooling rates) in the phase proportion calculation.

Figure 1 Evolution of the austenite proportion as a function of the temperature for different heating rates for an AISI5210 steel (see online version for colours)

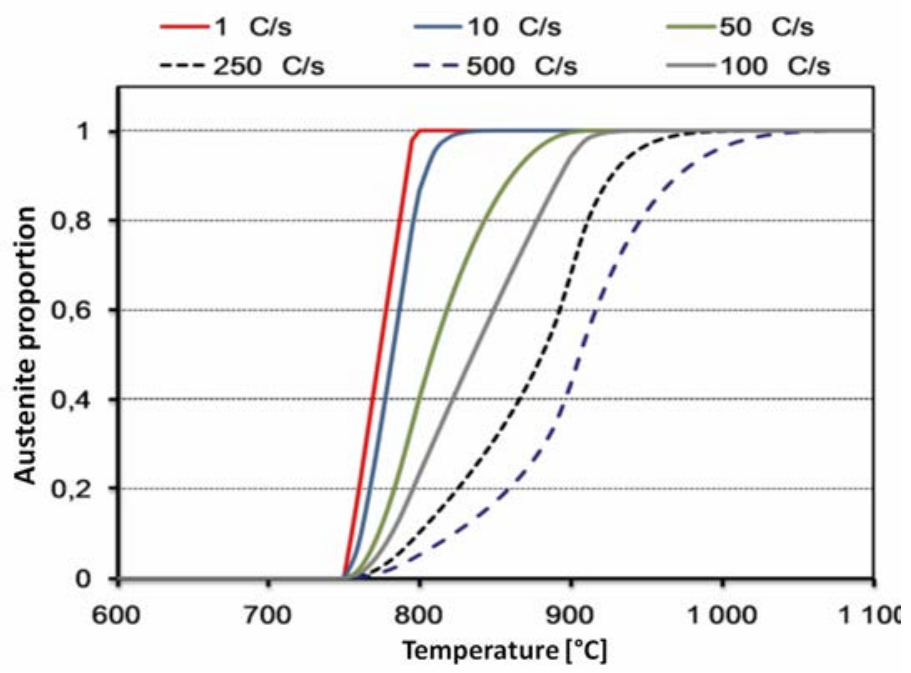

In Chou (2002)'s study, the effects of machining thermal kinetics are mentioned. Chou (2002) uses an equivalent analytically computed heat source moved on the machined surface to predict the surface hardening of AISI4340 steel. It gives a temporal response of temperature at $13 \mu \mathrm{m}$ below the surface. The maximum temperature reached is $1,300^{\circ} \mathrm{C}$ (with a heating rate higher than $5.5 \times 10^{6 \circ} \mathrm{C} / \mathrm{s}^{-1}$ ). Indeed Chou (2002) explains that the time interval during which the material was exposed above austenitising temperature (Ac3 of AISI4340 steel is set to $774^{\circ} \mathrm{C}$ ) is only $0.3 \mathrm{~ms}$, far shorter than the time scale in conventional surface hardening. Chou (2002) explains that such short time austenitising is in contradiction with the time-dependence of the autenitisation reaction. Then Chou (2002) suggests that stress/strain significantly contribute to the hardening process.

In other fields than machining, some authors have also tried to work on phase changes using metallurgical model adapted to high thermal kinetics. This is particularly the case for surface hardening treatments. Patwa and Shin (2007) explain the difficulty of considering the formation of austenite in the case of a laser surface heating. Indeed, this time-dependent transformation needs sufficient time for completion or would otherwise be completed only at a higher temperature. In other words, the smaller the time available for diffusion, the higher would be the required maximal reached temperature to obtain a completed austenitisation. Patwa and Shin (2007) describe a kinetic model describing pearlite dissolution and carbon redistribution in austenite to predict surface microstructure and hardness without the need of any experimental data. 
From a more experimental point of view, Mioković et al. (2006) and Mioković et al. (2007) study the surface hardening of AISI4140 steel by laser heating. To calibrate a suitable metallurgical model, Mioković et al. (2006) performs dilatometry tests with rapid heating (up to $10,000^{\circ} \mathrm{C} / \mathrm{s}^{-1}$ ) and cooling (up to $3,000^{\circ} \mathrm{C} / \mathrm{s}^{-1}$ ). This work perfectly illustrates the time dependence of the austenitic transformation (variation of the phase change temperatures) and its diffusive nature in the case of AISI4140 steel. Similarly, Reti et al. (1999) explain that the issue is the same during a surface heating by induction. The problem here is that, during a short cycle induction heating of 50 CrMo 4 steel, homogenous austenite may not be obtained. The proportion of transformed phase and so the steel hardness obtained after induction heating and rapid quenching are functions of heating time and final heating temperature. So, Reti et al. (1999) suggests a new phenomenological model and computational method to take into account this kinetic aspect.

Finally, it has been shown that it is important to consider thermal kinetics in an austenitisation model suitable for machining processes. Indeed, this problem of rapid austenitisation, well known in other fields of study for the prediction of phase changes for high thermal kinetics, must also be taken into account for machining. Then two major difficulties arise with this argument.

The first one is directly due to the thermal conditions of the machining process. A great number of studies have shown that metallic fabrication processes, and particularly machining, lead to extremely fast thermal cycles. Poulachon (1999) estimates the heating rate of steel during a hard turning operation to be $2.1 \times 10^{6}{ }^{\circ} \mathrm{C} / \mathrm{s}$. The analytical model of Burns et al. (2009) estimate the heating rate to be $1.62 \times 10^{6 \circ} \mathrm{C} / \mathrm{s}$ during orthogonal machining of AISI 1045 steel. Chou and Evans (1999) model estimates the cooling of an AISI52100 steel to be $-3.6 \times 10^{4} \circ \mathrm{C} / \mathrm{s}$ during dry turning whereas Mondelin et al. (2011)'s model quantifies the cooling rate at $-10^{6 \circ} \mathrm{C} / \mathrm{s}$ during the lubricated turning of AISI S15500 . This thermal kinetics is clearly different from cooling rates ordinarily associated with classical quenching operations (from $-170^{\circ} \mathrm{C} / \mathrm{s}$ to $-1,000^{\circ} \mathrm{C} / \mathrm{s}$ according to Krauss (1990) and Lee and Lee (2008). These very high cooling rates (even during dry machining) are mainly due to the heat conduction from the small cutting zone to the rest of the part.

The second difficulty is related to the nature of the austenitisation reaction itself in superheating conditions. Indeed, extremely high heating rates seem to go against the classical decomposition of martensite into austenite by carbon diffusion (time-dependent nature of diffusional phase transformation). Nevertheless, studies of Leem et al. (2001) and Kappoor and Batra (2004) have shown that the transformation of martensite to austenite can also occur without diffusion using an operation called 'reverse transformation'. It means that the phase change does not occur with the long-range diffusion of atoms but rather with a form of movement (sliding and shearing) of the atomic planes. In the literature these two types of austenite transformation according to the heating rate have been reported. The debate on the displacive $\alpha \rightarrow \gamma$ transformation under high thermal kinetics is still a controversial subject. So, the point is to choose experimental criteria to distinguish these two modes of transformation during rapid heating. The variation of Ac1 and Ac3 (start and end temperature of the austenite transformation) with the heating rate is often considered.

For example, Leem et al. (2001) have studied a martensitic low carbon stainless steel (such as the AISI S15500). According to Leem et al. (2001), below a heating rate of 
$10^{\circ} \mathrm{C} / \mathrm{s}$ the austenite transformation is performed by diffusion. Above $10^{\circ} \mathrm{C} / \mathrm{s}$, it is performed by a diffusionless shear mechanism (the reverse martensitic transformation). This conclusion is justified by the dependence of Ac1 and Ac3 (start and end temperature of the austenite transformation) on the heating rate below $10^{\circ} \mathrm{C} / \mathrm{s}$. On the contrary, above $10^{\circ} \mathrm{C} / \mathrm{s}$, Ac1 and Ac3 become stable. Moreover, Kappoor and Batra (2004) deal with the effects of the heating rate on the austenite transformation kinetics in 17-4PH steel (a martensitic stainless steel close to AISI S15500). Their conclusions show that the austenite transformation is performed by diffusion at low rates and by a shearing process at high rates. Their conclusions are based on the analysis of the activation energy required for austenite formation. Nevertheless, contrary to what happens in Leem et al. (2001)'s study, Ac1 and Ac3 temperatures are not stabilised and keep rising as the heating rate increases. This contradicts Leem et al. (2001)'s study in which the variation of Ac1 and Ac3 with the heating rate demonstrates a diffusion mode of transformation. Constant et al. (1992), basing their assumptions on Orlich et al. (1973)'s study, show curves illustrating the transformation of an AISI4135 steel during rapid heating without a holding temperature. The maximal heating rate is $2,400^{\circ} \mathrm{C} / \mathrm{s}$ which is a very high value in the literature (generally, heating rates used to calibrate metallurgical models are ten times lower, close to $100^{\circ} \mathrm{C} / \mathrm{s}$ ). A permanent variation (increase) of Ac1 and Ac3 temperatures has been observed when the heating rate rises. There is no stabilisation of these temperatures [Ac1 and Ac3 stabilisation is considered by Leem et al. (2001) as a consequence of diffusionless transformation].

Studies related to the austenite transformation kinetics of AISI S15500 are very rare. Wu (2007)'s works deal with the characterisation of AISI S15500 phase changes in order to model its welding. Nevertheless, heating rates are limited to $5^{\circ} \mathrm{C} / \mathrm{s}$. Similarly, Herny et al. (2008) study AISI S15500 heating up to $1,050^{\circ} \mathrm{C}$ but the results are principally focused on copper precipitation phases and the heating and cooling rates are very low $\left(5^{\circ} \mathrm{C} / \mathrm{min}\right)$.

With regard to diffusive transformations (like austenitisation), differential formulations are generally used. Leblond and Devaux (1984) phenomenological model is based on a simple law:

$$
\dot{Z}_{\gamma}=\frac{Z_{e q}-Z_{\gamma}}{\tau}
$$

where $\dot{Z}_{\gamma}$ is the austenite transformation rate, $Z_{e q}$ is the volumic proportion of austenite in equilibrium (i.e., considering an infinite isothermal holding temperature), $Z_{\gamma}$ is the current volumic proportion of austenite and $\tau$ is a constant of time (a 'delay'). This model gives good results for ferritic, perlitic and austenitic transformations but is unable to reproduce faster transformations (like the bainitic one) correctly (Wu, 2007). So an intermediate formulation extracted from equation (1) can be utilised where $Z_{e q}$ and $\tau$ are directly dependent on the temperature $T$ but also on the heating rate $\dot{T}$ [equation (2)]:

$$
\dot{Z}_{\gamma}=\frac{Z_{e q}(T, \dot{T})-Z_{\gamma}}{\tau(T, \dot{T})}
$$

The influence of the different model parameters $\left(Z_{e q}, \tau\right.$, Ac1 and Ac3) is illustrated in Figure 2 showing the austenite proportion $Z_{\gamma}$ as a function of the temperature $T$ for different heating rates $\left(\dot{T}_{1}, \dot{T}_{2}, \dot{T}_{3}\right)$. Finally, this form of Leblond's model is utilised in the 
rest of this study because of the simplicity of its parameters and its identification, its easy implementation in finite element calculation codes and its good adequacy to model anisothermal diffusive transformations (time-dependent transformations). Various approaches and improvements make it possible to take into account other transformation characteristics (grain size, carbon concentration, ...) which will not be developed here.

Figure 2 Influence of Leblond model parameters (see online version for colours)

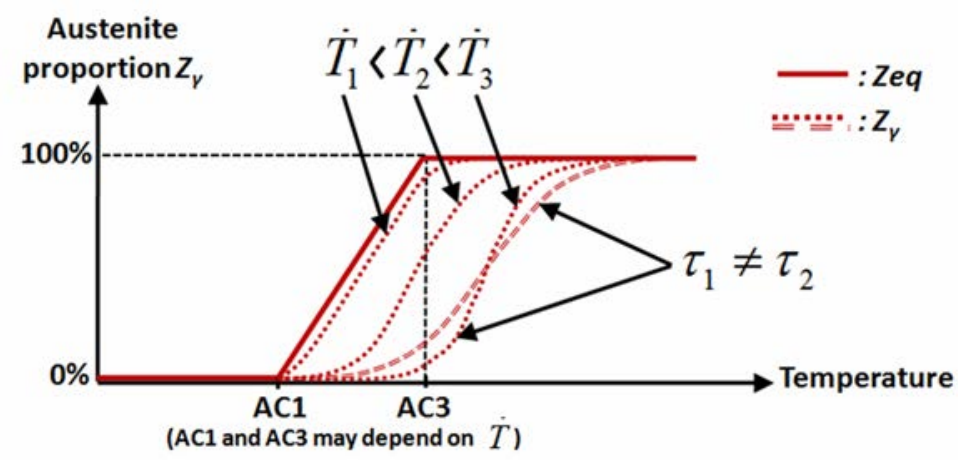

Experimental resources used to calibrate metallurgical models are multiple in the literature. With regard to heating devices, the Joule effect heating (by induced or direct current) is widely used. The stress-free dilatometry method, used by Leem et al. (2001) and Kappoor and Batra (2004) for example, consists in measuring the deformation of a sample subjected to no stress except for the thermal one (Figure 3). The beginning of the phase transformation is identified by the loss in the linearity of the temperature-deformation curve.

Figure 3 Experimental set-up: positioning the sample in the Gleeble jaws and locations of temperature and dilatation measurements on the stress-free dilatometry sample (see online version for colours)
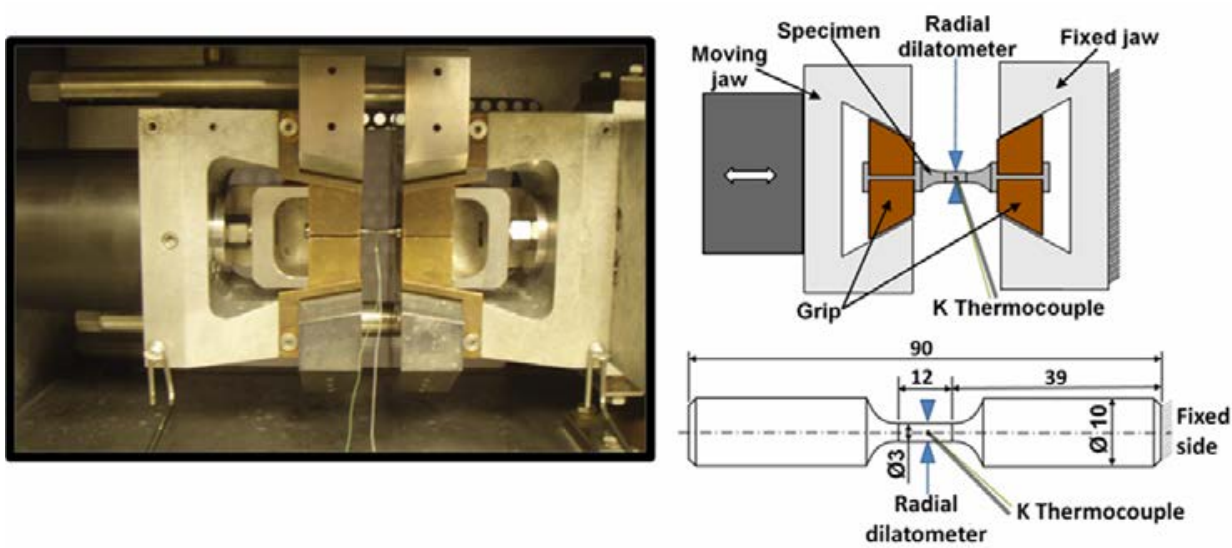

Moreover, this type of curve permits to obtain the proportion of phase formed during the transformation as shown by Leblond et al. (1986). Indeed, during stress-free dilatometry, the total deformation is equal to the thermal deformation. Moreover the mean thermal 
deformation between temperatures $T_{o}$ and $T$ is equal to $k_{k}\left(T-T_{o}\right)$ for a phase $k$ with a dilatation coefficient $k_{k}$. So equation (3) highlights the direct relationship between the dilatometry curve and phase proportion in the material:

$$
Z_{\gamma}=\frac{E^{\text {therm }}-k_{\alpha^{\prime}}(T-T o)-\Delta \varepsilon_{\alpha^{\prime} \gamma}^{T o}}{\left(k_{\gamma}-k_{\alpha^{\prime}}\right)(T-T o)-\Delta \varepsilon_{\alpha^{\prime} \gamma}^{T o}}
$$

where the subscript indicates the averaged phase and $\Delta \varepsilon_{\alpha^{\prime} \gamma}^{T o}$ is the volumetric density difference between the $\alpha$ ' phase and the $\gamma$ phase at temperature $T_{o}$.

Thus, the stress-free dilatometry method has been chosen for this study. The capacities of the thermo-mechanical simulator Gleeble ${ }^{\circledR}$, coupled with the specific sample shape, permit to reach high heating rates and measure the resulting deformations with great accuracy.

Therefore, a stress-free dilatometry study has been performed for heating rates from $6^{\circ} \mathrm{C} / \mathrm{s}$ to $11,000^{\circ} \mathrm{C} / \mathrm{s}$. This very wide range allows focusing on Ac1 and Ac3 temperature variations according to thermal kinetics first. So based on these results, the time-dependent nature of the martensite to austenite transformation is revealed over the whole heating rate range. The parameters of Leblond model (Leblond and Devaux, 1984) are calibrated for the thermal kinetics studied. Then the calibrated metallurgical model is combined with a thermal cycle (heating and cooling phase) characteristic of a turning operation. The proportion of austenite formed during this machining operation is then computed.

\section{Stress-free dilatometry study}

\subsection{Experimental set-up}

The aim of this stress-free dilatometry study is to deal with phase changes (and in particular the austenisation rate) at very high heating rates. Experiments are carried out to extract two types of information: the variations of Ac1 and Ac3 temperatures and the transformation activation energy according to the heating rate.

The material studied is an AISI S15500 (also known as 15-5PH steel), a martensitic precipitation-hardening stainless steel in H1025 (40 HRC) conditions. The chemical composition of an AISI S15500 steel in wt\% is listed in Table 1.

Table 1 Chemical composition of AISI S15500 stainless steel in wt\%

\begin{tabular}{lccccccccc}
\hline$C$ & $M n$ & $S i$ & $C r$ & $N i$ & $C u$ & $N b$ & $S$ & $P$ & $F e$ \\
\hline 0.07 & 1.0 & 1.0 & 14 to & 3.5 to & 2.5 to & 0.15 & 0.03 & 0.04 & Bal. \\
Max. & Max. & Max. & 15.5 & 5.5 & 4.5 & 0.45 & Max. & Max. & \\
\hline
\end{tabular}

The capacities of the thermo-mechanical power-controlled simulator Gleeble ${ }^{\circledR}$ were used to reach high heating rates. The heating, produced by Joule effect, depends on the current intensity transmitted and is located in the smallest diameter zone of the sample (Figure 3). 
Dilatation measurements are performed by means of a radial dilatometer. This method permits to eliminate problems related to important axial temperature gradients. The temperature measurements are performed by means of an $80 \mu$ m diameter (type K) thermocouple welded on the measured diameter of the sample.

Each measurement was replicated at least twice. The maximal measurement uncertainty was set to $\pm 20^{\circ} \mathrm{C}$ for Ac1 and $\pm 35^{\circ} \mathrm{C}$ for Ac3 for the highest heating rates. This is due to the difficulty to precisely locate the loss in the linearity of the temperature-deformation curve and measurement reproducibility.

Heating is quasi-linear (Figure 4) and lasts from $160 \mathrm{~s}$ (up to $960^{\circ} \mathrm{C}$ at $6^{\circ} \mathrm{C} / \mathrm{s}$ ) to $0.1 \mathrm{~s}$ (up to $1,100^{\circ} \mathrm{C}$ at $11,000^{\circ} \mathrm{C} / \mathrm{s}$ ). Cooling is free (convection with ambient air and conduction with the clamping jaws). The maximal cooling rate is about $-90^{\circ} \mathrm{C} / \mathrm{s}$ when heating stops.

One of the sample extremities is fixed; the other is free to move axially. Nevertheless, constant friction forces on the moving jaw induce residual stresses on the specimen (about $80 \mathrm{~N} \rightarrow 11 \mathrm{MPa}$ ) without any notable effects on dilatometry measurements (Figure 5).

Figure 4 Thermal cycle (a) heating and cooling (b) example of time temperature derivative during heating at $7,500^{\circ} \mathrm{C} / \mathrm{s}$ (see online version for colours)
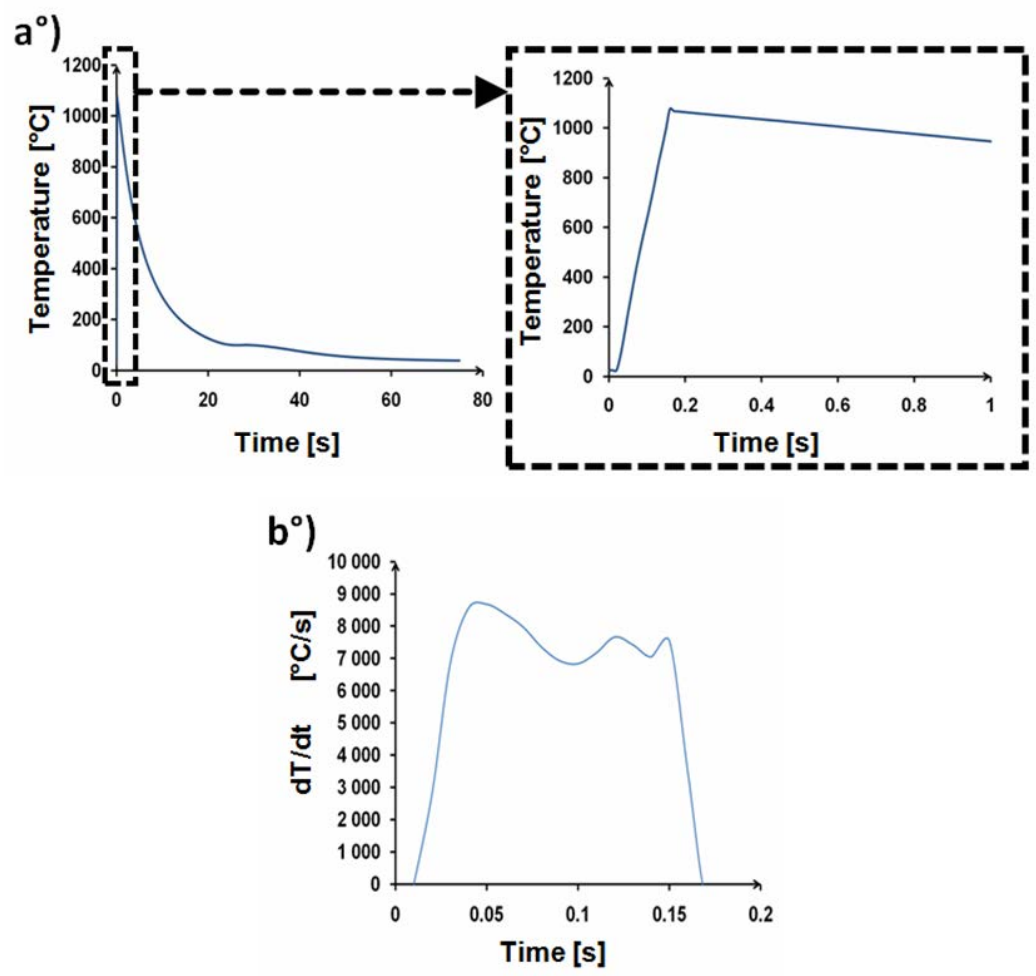
Figure 5 Stress-free dilatometry measurements for heating rates from $6^{\circ} \mathrm{C} / \mathrm{s}$ to $11,000{ }^{\circ} \mathrm{C} / \mathrm{s}$ (see online version for colours)

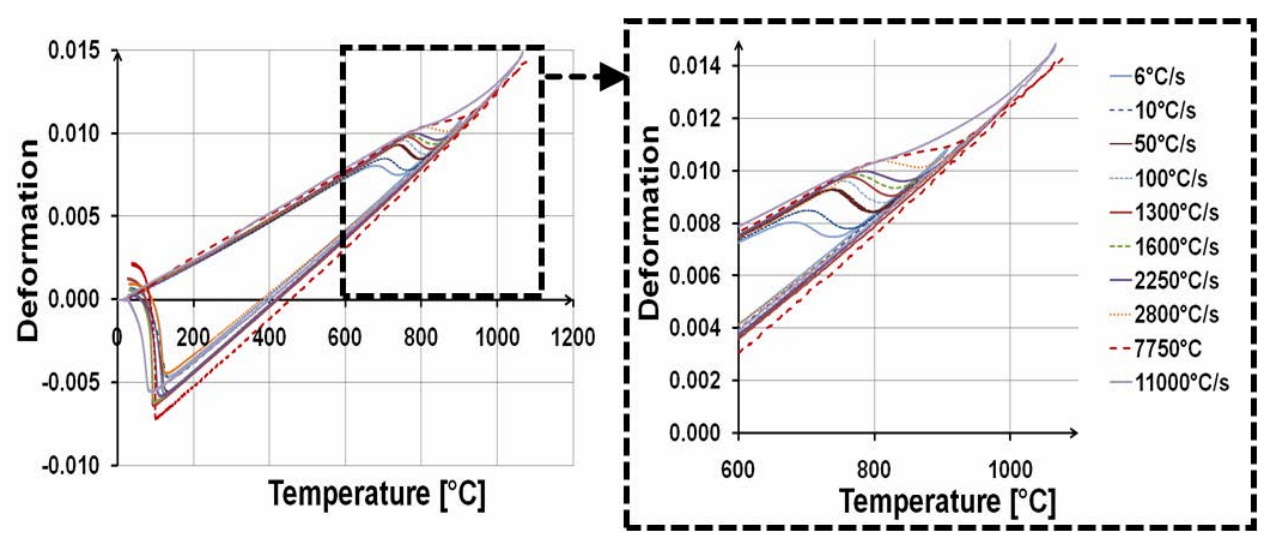

Figure 6 Variation of austenite transformation start and end temperatures according to the heating rate (see online version for colours)

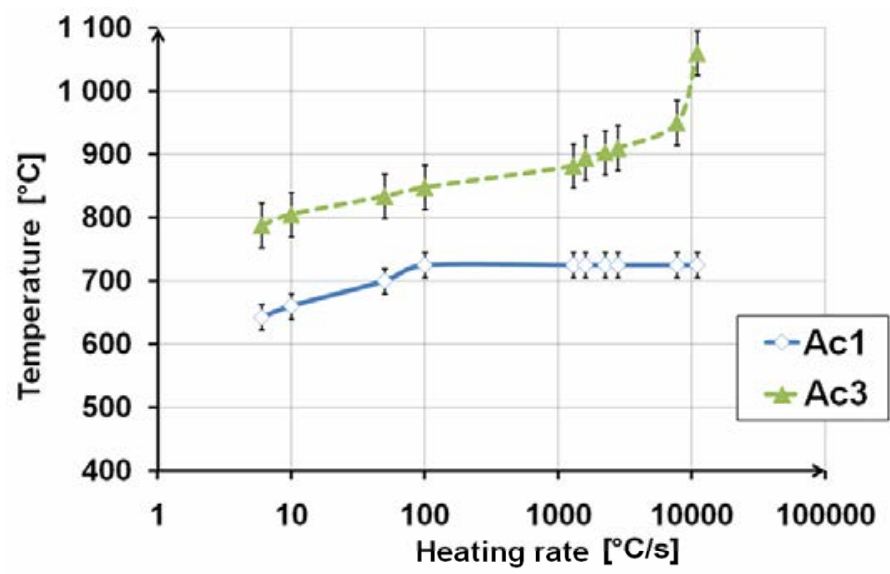

\subsection{Dilatometry results}

A dilatometric curve permits to obtain the proportion of phase formed during the transformation as shown by Leblond et al. (1986). The beginning of the phase transformation is identified by the loss in the linearity of the temperature-deformation curve.

Figure 5 represents stress-free dilatometry results for various heating rates from $6^{\circ} \mathrm{C} / \mathrm{s}$ to $11,000^{\circ} \mathrm{C} / \mathrm{s}$.

The evolution of austenite formation according to the heating rate can be divided into two zones (Figures 5 and 6). For heating rates from $6^{\circ} \mathrm{C} / \mathrm{s}$ to $100^{\circ} \mathrm{C} / \mathrm{s}$, the transformation rate increases and the austenisation range is slightly reduced (from $146^{\circ} \mathrm{C}$ to $123^{\circ} \mathrm{C}$ between Ac1 and Ac3). The transformation start temperature Ac1 shifts to higher temperatures (from $642^{\circ} \mathrm{C}$ to $720^{\circ} \mathrm{C}$ ). 
Then for heating rates from $1,300^{\circ} \mathrm{C} / \mathrm{s}$ to $11,000^{\circ} \mathrm{C} / \mathrm{s}$, temperature Ac1 stabilises around $725^{\circ} \mathrm{C}$. On the contrary, temperature Ac3 still increases. So the austenisation range increases to reach $335^{\circ} \mathrm{C}$ at $11,000^{\circ} \mathrm{C} / \mathrm{s}$. The time-dependent nature of the martensite to austenite transformation is revealed over the whole heating rate range.

\subsection{Summary}

Finally, with the stress-free dilatometry study, one can notice that the start and end austenite formation temperatures (Ac1 and Ac3) remain directly dependent on the thermal kinetics. Indeed, although Ac1 stabilises, the austenisation range still increases with the heating rate augmentation even for higher values. This obvious relationship between heating rate and transformation kinetics is opposed to the principle of a displacive type transformation (where the transformation rate is directly governed by the temperature) according to Leem et al. (2001). It seems to be more consistent with a diffusion transformation (time-dependent nature of the $\alpha^{\prime} \rightarrow \gamma$ transformation).

So, the change from a classical austenite transformation by carbon diffusion to a temperature-dependent only transformation cannot be applied to our study. The time-dependent nature of the transformation is present over the whole heating rate range tested (through the dependence of Ac1 and Ac3 on thermal kinetics). That is why the continuity of the austenite transformation diffusional nature can be put forward.

The model to be identified in order to simulate the austenite transformation over this heating rate range should be adapted to anisothermal time-dependent transformations. This corresponds to the characteristics and validity domain of Leblond's model previously introduced. Then the use and calibration of Leblond's model are suitable for modeling AISI S15500 microstructural changes.

\section{Identification of Leblond's model parameters adapted to high thermal kinetics}

\subsection{Assumptions and model parameters}

The parameters of Leblond's model are identified to reproduce stress-free dilatometry results from the following data: heating rate, cooling rate and maximal temperature reached. In particular, the aim of this identification is to simulate high heating kinetics (higher than $500^{\circ} \mathrm{C} / \mathrm{s}$ ). In order to ensure the continuity with lower heating and cooling rates, parameters are calibrated in the range from $6^{\circ} \mathrm{C} / \mathrm{s}$ to $11,000^{\circ} \mathrm{C} / \mathrm{s}$.

Leblond's model is presented in the introduction by means of equation (2). Its different parameters $Z_{e q}, \tau$, Ac1 and Ac3 are calibrated using the stress-free dilatometry study. Assumptions related to the evolution of these parameters are taken into account and introduced in the following paragraph:

Given the variations Ac1 and Ac3 have been subjected to during the evolution of the heating rate, $Z_{e q}$ is considered to be dependent on the temperature but also on the heating rate. The evolution of $Z_{e q}$ between $A c 1 Z_{\text {eq }}$ and $A c 3 Z_{\text {eq }}$ is considered to be linear (from $0 \%$ to $100 \%)$. 


$$
\begin{aligned}
& \mathrm{Ac} Z_{\text {eq }} \text { : } \\
& |\dot{T}|<6^{\circ} \mathrm{C} / \mathrm{s} \rightarrow \mathrm{Ac} 1 Z_{e q}=642^{\circ} \mathrm{C} \\
& |\dot{T}|>380^{\circ} \mathrm{C} / \mathrm{s} \rightarrow \mathrm{Ac} 1 Z_{e q}=765^{\circ} \mathrm{C} \\
& 6^{\circ} \mathrm{C} / \mathrm{s}<|\dot{T}|<380^{\circ} \mathrm{C} / \mathrm{s} \rightarrow \mathrm{Ac} 1 Z_{e q}=597|\dot{T}|^{004} \\
& {\operatorname{Ac} 3 Z_{e q}:} \\
& |\dot{T}|<6^{\circ} \mathrm{C} / \mathrm{s} \rightarrow \mathrm{Ac} Z_{e q}=754^{\circ} \mathrm{C} \\
& |\dot{T}|>200^{\circ} \mathrm{C} / \mathrm{s} \rightarrow{\mathrm{Ac} 3 Z_{e q}}=830^{\circ} \mathrm{C} \\
& 6^{\circ} \mathrm{C} / \mathrm{s}<|\dot{T}|<200^{\circ} \mathrm{C} / \mathrm{s} \rightarrow{\mathrm{Ac} 3 Z_{e q}}=717|\dot{T}|^{003}
\end{aligned}
$$

The delay time connected to the reaction is considered to be dependent on the heating rate. In order to reproduce the increase in the austenisation rate during the transformation, its value will be linearly reduced by $60 \%$ between Ac1 and Ac3. This reduction was calibrated so as to obtain the best compromise for all heating rates.

Delay time $\tau$ :

$$
\begin{aligned}
& |\dot{T}|<6^{\circ} \mathrm{C} / \mathrm{s} \rightarrow \tau=8.75 \mathrm{~s} \\
& |\dot{T}|>1,300^{\circ} \mathrm{C} / \mathrm{s} \rightarrow \tau=0.026 \mathrm{~s} \\
& 6^{\circ} \mathrm{C} / \mathrm{s}<|\dot{T}|<1,300^{\circ} \mathrm{C} / \mathrm{s} \rightarrow \tau=36 /|\dot{T}|
\end{aligned}
$$

Austenite transformation can continue during cooling if the austenite proportion does not reach $100 \%$ at the end of the heating process and as long as the temperature remains higher than Ac1. This assumption, confirmed by Katsamas (2007)'s study, is important for the simulation of fast heating (which does not allow complete austenite transformation). The evolution of the model parameters and its dependence on $|\dot{T}|$ are considered to be identical during heating or cooling.

Finally, it is possible to note that, for $|\dot{T}|$ higher than $1,300^{\circ} \mathrm{C} / \mathrm{s}$, the model is simplified because all the model parameters $\left(Z_{e q}, \tau, \ldots\right)$ become independent from $|\dot{T}|$. Indeed, according to the identification of the model parameters, from $1,300^{\circ} \mathrm{C} / \mathrm{s}$ all parameters have a fixed value: $\mathrm{Ac}_{\mathrm{C}} \mathrm{Z}_{\mathrm{eq}}=765^{\circ} \mathrm{C}$; $\mathrm{Ac}_{3 \mathrm{Z}}=830^{\circ} \mathrm{C} ; \tau=0.026 \mathrm{~s}$. Since the identification leads to a stabilisation of parameters, the evolution of the austenisation rate only depends on the model reaction [equation (2)] to thermal kinetic variations (during heating or cooling). The validation of the model identification will be presented hereafter up to $11,000^{\circ} \mathrm{C} / \mathrm{s}$.

\subsection{Modelling the stress-free dilatometry test}

In order to compare the results of calibrated Leblond model with experimental data, it is possible to simulate a complete stress-free dilatometry test. To do so, equation (3) is used with the following coefficients (non-thermally dependent): 


$$
\begin{aligned}
& \Delta \varepsilon_{\alpha^{\prime} \gamma}^{T o} \\
& -\Delta \varepsilon_{\alpha^{\prime} \gamma}^{T o}=-8 \times 10^{-3}\left(\text { for } T_{o}=20^{\circ} \mathrm{C}\right) \\
& -k_{\alpha^{\prime}}=1.45 \times 10^{-5} \\
& -k_{r}=2.2 \times 10^{-5}
\end{aligned}
$$

These parameters (coefficient of thermal expansion and volumetric density difference at $20^{\circ} \mathrm{C}$ ) are directly measured on the experimental curves of stress-free dilatometry.

Martensitic transformation, which occurs at the end of the cooling process, is simply modeled by means of Koïstinen and Marburger (1959) law [equation (4)]:

$$
Z_{\alpha^{\prime}}(T)=Z_{\gamma} \cdot(1-\exp (-\beta \cdot[M s-T]))
$$

More recently, Lee and Lee (2008) proposed a new kinetics equation for the martensitic transformation that considered the influence of austenite grain size, the shape of the kinetics curve of the martensite fraction vs. temperature, and alloying elements.

Within the framework of this study (the focus is on austenitisation during the heating phase), the Koïstinen and Marburger law [equation(4)] is used and its parameters are fixed and independent from the thermal cycle. Therefore, from the stress-free dilatometry data, it is possible to evaluate the value of $M s=170^{\circ} \mathrm{C}$ (average value). $\beta$ is set to 0.02 to reproduce in the best possible way the average kinetics of the martensitic transformation.

Then, the curves in Figure 7 are obtained. They show the variation of the stress-free expansion of a unitary volume according to different heating rates (ranging from $6^{\circ} \mathrm{C} / \mathrm{s}$ to $11,000^{\circ} \mathrm{C} / \mathrm{s}$ ). The agreement with experimental data (Figure 5 and Figure 8) confirms the identified values of the metallurgic model parameters. It is important to note, among other things, the evolution of temperatures Ac1 and Ac3 for heating rates up to $1,300^{\circ} \mathrm{C} / \mathrm{s}$. Then, Ac1 stabilises but Ac3 keeps rising (so there is an increasing austenisation range).

Figure 7 Modeling stress-free dilatometry tests using Leblond model calibrated parameters (see online version for colours)

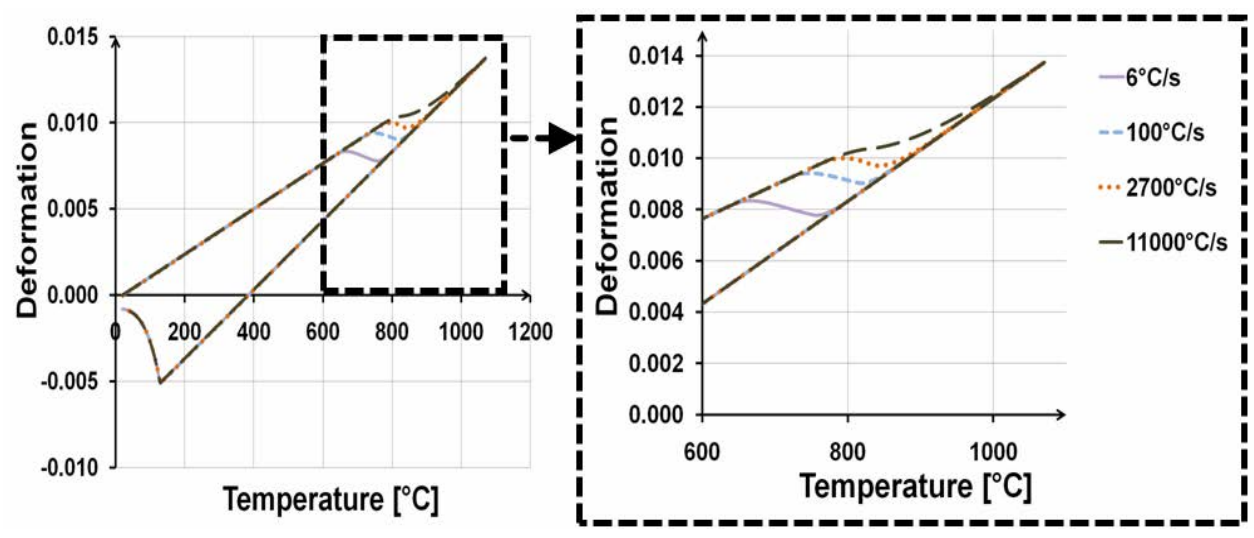


Considering the very low differences between calibrated model results and experimental data during austenite transformation (Figure 8), it is possible to conclude that the assumptions related to the evolution of Leblond model parameters and identified values are justified and relevant.

Finally, it is essential to note how important it is to calibrate the transformation kinetics model using high heating rates. For AISI S15500 steel, trying to calibrate a transformation model with low heating rates $\left(6^{\circ} \mathrm{C} / \mathrm{s}\right.$ for example) is inadequate to reach steady values of the model parameters. Dilatometry tests up to $11,000^{\circ} \mathrm{C} / \mathrm{s}$ allow us to reach thermal kinetics where Leblond model parameters are stabilised. Therefore, the extrapolation to higher thermal kinetics is justified. So for AISI S15500 steel, the minimum heating rate for the calibration of the transformation model seems to be around $1,300^{\circ} \mathrm{C} / \mathrm{s}$ (= stabilisation temperature of all parameters).

Figure 8 Comparison between experimental data and results of the calibrated model for different heating rates (see online version for colours)
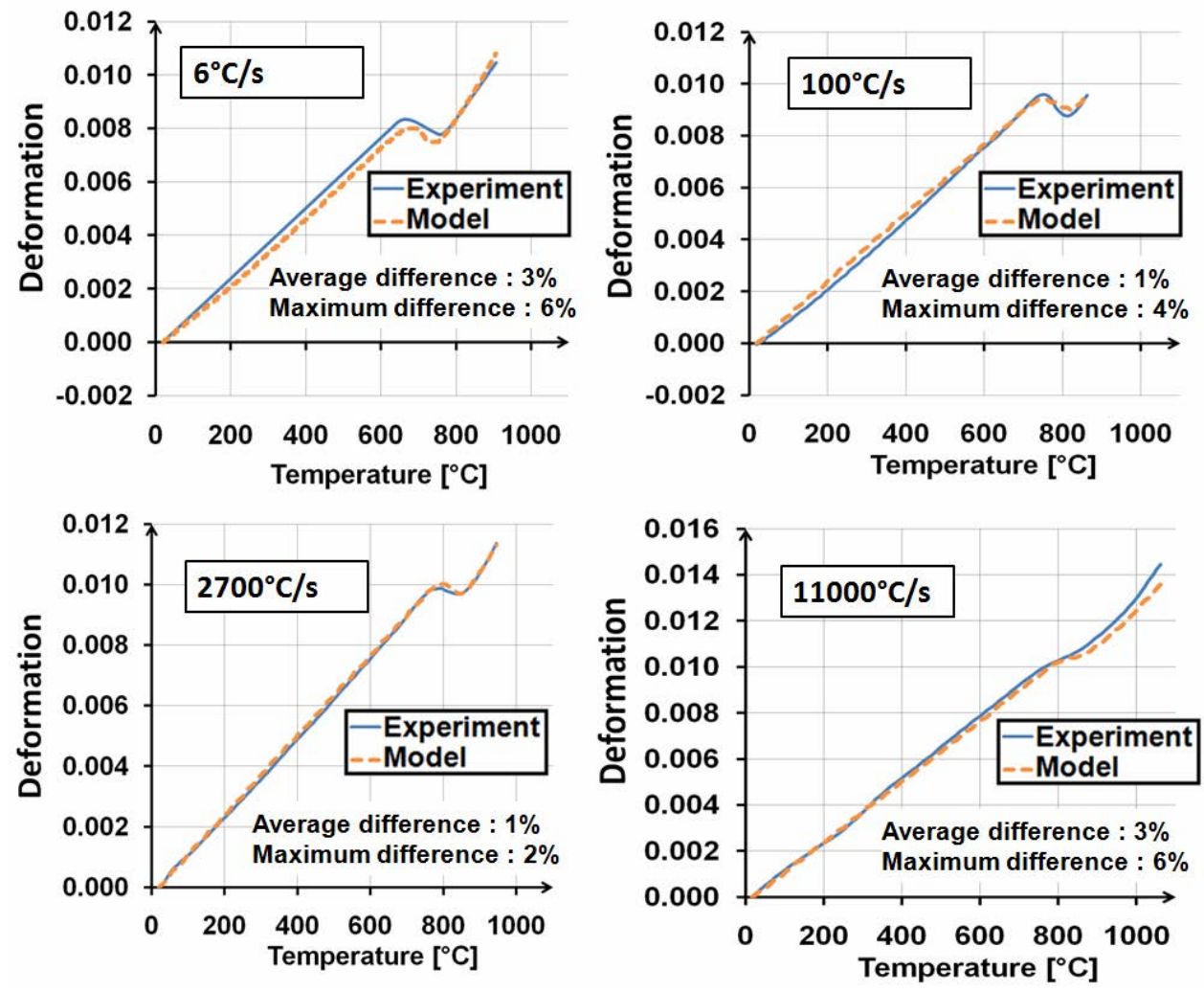


\section{Phase transformation during the finish turning of AISI S15500}

\subsection{Extraction of machining thermal kinetics}

The previously calibrated metallurgical model can be used to predict a possible phase transformation during an operation of finish turning on an AISI S15500 steel.

Using a machining model, it is possible to extract the thermal cycle undergone by the surface during a finish turning operation. The approach of the machining model used consists in replacing tool and chip modeling by equivalent loadings (Figure 9). These equivalent loadings are moved onto the machined surface. This model is called 'hybrid' because it applies thermo-mechanical loadings (obtained experimentally) to a numerical model.

The numerical machining model used to extract a typical machining thermal cycle is fully described in Mondelin et al. (2012)'s and Valiorgue et al. (2012)'s studies.

Figure 9 Principle of the hybrid model (see online version for colours)
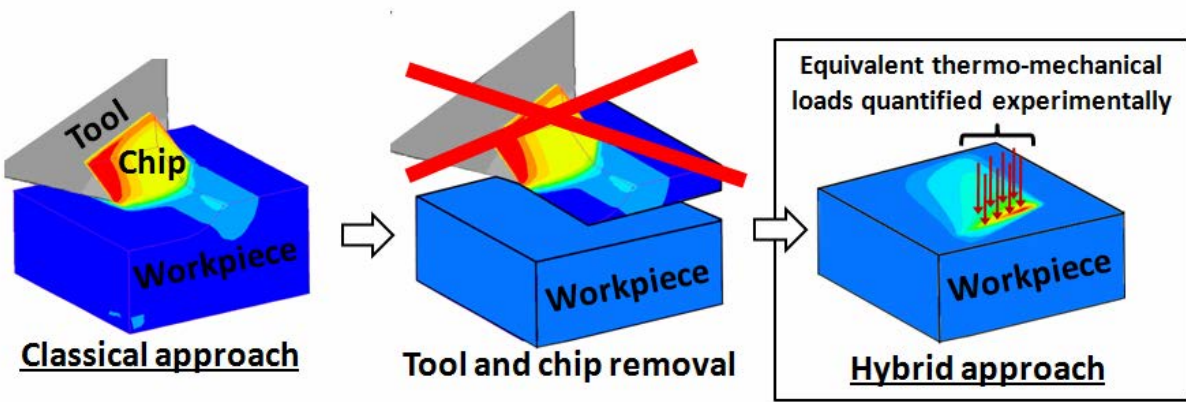

For the machining simulation, the following cutting conditions are considered for the turning of a $180 \mathrm{~mm}$ diameter cylinder of AISI S15500 steel:

- $\quad$ cutting speed Vc = $300 \mathrm{~m} \cdot \mathrm{min}-1$

- $\quad$ feed $\mathrm{f}=0.18 \mathrm{~mm}$ rev-1

- $\quad$ depth of cut: ap $=0.6 \mathrm{~mm}$

- dry cutting

- $\quad$ DNMG 150612 carbide insert with a Al2O3-TiCN coating.

The thermal cycle extracted using the hybrid model is presented in Figure 10(a). The maximal predicted temperature reached is $960^{\circ} \mathrm{C}$ (at the surface). In the depth, maximal temperatures rapidly go down. At $60 \mu \mathrm{m}$ below the machined surface, the material does not reach $200^{\circ} \mathrm{C}$.

Figure 10(b) presents corresponding thermal kinetics. The heating rate is around

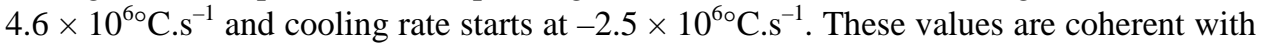
the values predicted by Poulachon (1999) and Chou (2002) for example. It illustrates the extreme thermal conditions of a machining operation. 
Figure 10 Temperatures extracted from a numerical hybrid model as functions of depth and time (a) thermal cycle characteristic of a turning operation of AISI S15500 steel (b) heating and cooling rates
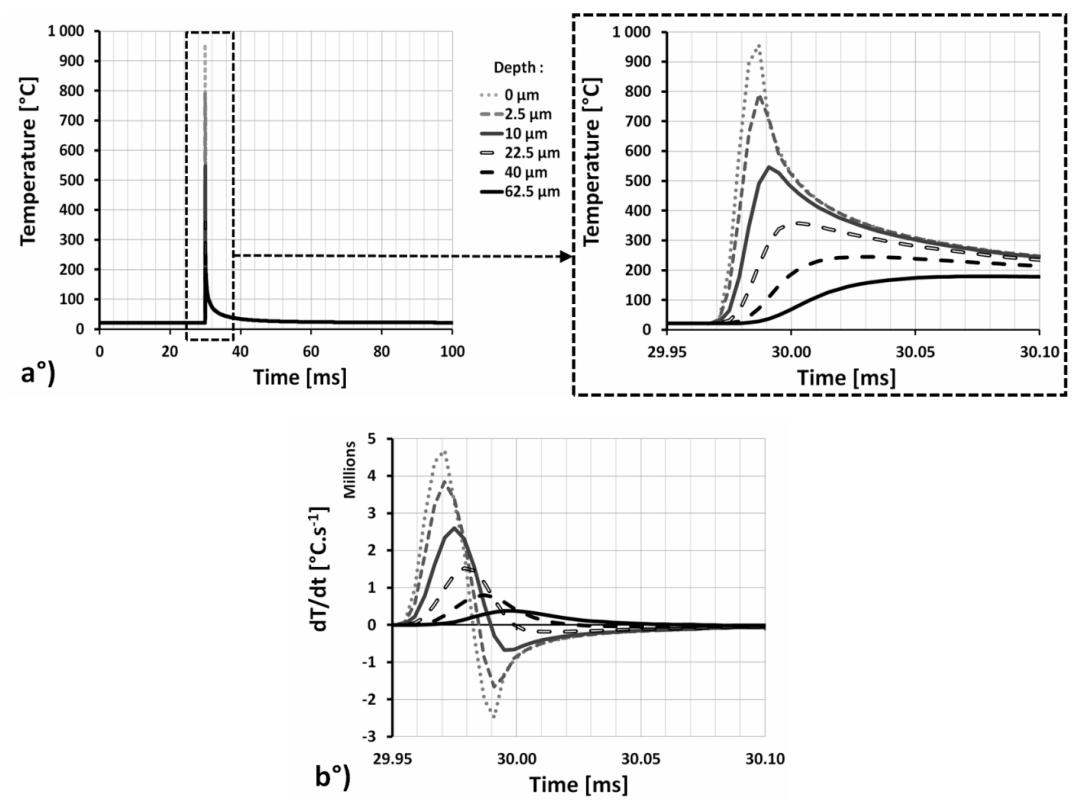

\subsection{Prediction of austenitisation using the calibrated metallurgical model of Leblond}

Firstly, it is important to note that the austenite start transformation temperature Ac1 calibrated for a low heating rate is $642^{\circ} \mathrm{C}$ for AISI S15500 steel (Figure 4). The maximal predicted temperature reached during turning is $960^{\circ} \mathrm{C}$, so it is $318^{\circ} \mathrm{C}$ higher than the Ac1 temperature (measured for low heating rates). This observation leads to conclude that austenite transformation may occur.

Figure 11 Proportion of austenite formed as a function of the temperature during the turning of AISI S15500 steel
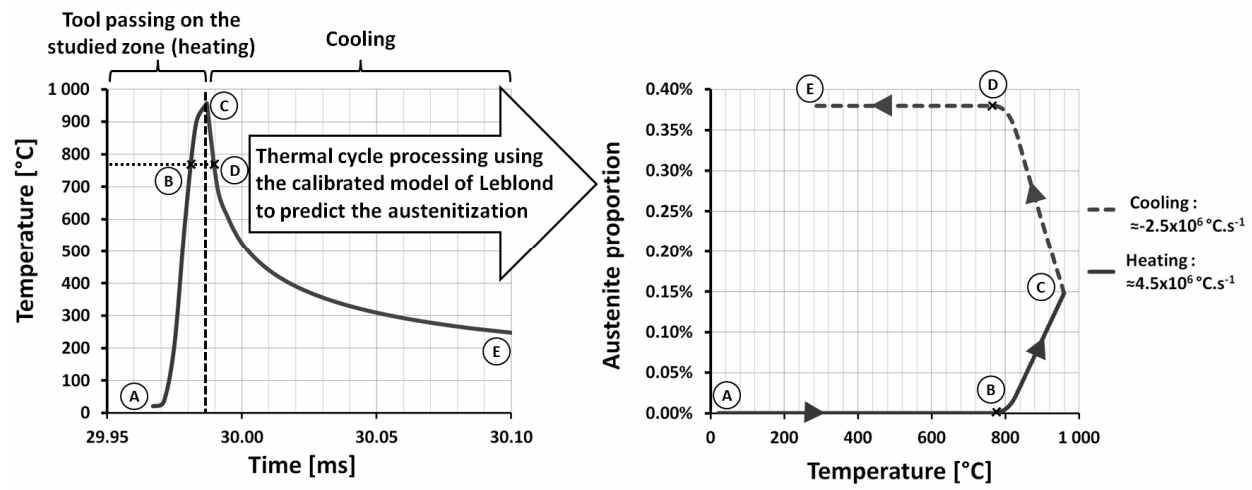
So, the previously calibrated Leblond metallurgical model has been applied with the machining thermal cycle of Figure 10. Results are presented in Figure 11.

Between reference points $A$ and $C$, the cutting-tool is in contact with the workpiece surface. It is the heating time. The cooling of the material occurs after the reference point C.

With the assumption that the initial proportion of austenite is nil $(100 \%$ of martensite), the machining thermal cycle produces only $0.37 \%$ of austenite for a maximum temperature of $960^{\circ} \mathrm{C}$. Only $0.15 \%$ of austenite is created during the heating phase (between reference points $B$ and $C$ ), so the austenite transformation continues during the cooling phase (between reference points $C$ and $D$ ).

With the machining thermal kinetics, the metallurgical model uses an austenite start temperature $A c 1$ of $775^{\circ} \mathrm{C}$. The time interval during which the material was exposed above austenitising temperature (Ac1) is only $0.01 \mathrm{~ms}$ (between reference points $B$ and D).

This example highlights the importance of calibrating metallurgical transformation models at high heating rates. It shows that the thermal kinetics does not allow a significant formation of austenite even if the maximal temperature reached is clearly higher than the austenisation start temperature.

\subsection{Retained austenite measurements in the machined surface layer}

Simulations, using the previously calibrated metallurgical model, show that austenitisation does not have the time to occur during the finish turning of AISI S15500 steel (even if high temperatures are reached). Moreover, experimental measurements can be used to confirm these numerical predictions. Umbrello (2011) for example, warrant the presence of austenitisation during turning using quantification of retained austenite proportion in the machined surface. Umbrello (2011) shows a significant increase of the retained austenite proportion in the machined surface compared with the original material. The same approach has been used in this study. Retained austenite proportion has been measured using X-ray diffraction method. Cutting conditions used to produce the machined surface are the same as previously presented (cutting speed $\mathrm{Vc}_{\mathrm{c}}=$ $300 \mathrm{~m} \mathrm{~min}^{-1}$; feed $\mathrm{f}=0.18 \mathrm{~mm} \mathrm{rev}^{-1}$; ap $=0.6 \mathrm{~mm}$; dry cutting). Results are presented in Table 2.

Contrary to the study of Umbrello (2011), the retained austenite proportion decreases during machining from $7.3 \%$ in the original material to $4.5 \%$ in the machined surface. This experimental observation leads to two conclusions. Firstly, there was not a significant austenitisation of AISI S15500 during the turning operation (which would have led to an increase of the retained austenite proportion). This conclusion is consistent with the results of the numerical simulations. Secondly, even if the austenitisation does not occur massively during machining, it does not prevent the martensitic transformation to occur during cooling (quenching of retained austenite due to the very high cooling rate). This conclusion may explain the small decrease in the retained austenite proportion after machining. 


\begin{tabular}{lccc}
\hline & $\begin{array}{c}\text { Retained austenite } \\
\text { proportion (\%) }\end{array}$ & $\begin{array}{c}\text { Martensite } \\
\text { proportion (\%) }\end{array}$ & $\begin{array}{c}\text { Standard deviation of the } \\
\text { austenite proportion measurement } \\
\text { (\%) }\end{array}$ \\
\hline $\begin{array}{l}\text { Original } \\
\text { material } \\
\begin{array}{l}\text { Machined } \\
\text { surface }\end{array}\end{array}$ & 7.3 & 92.7 & 0.2 \\
\hline
\end{tabular}

\section{Discussion}

With regard to the issues presented in the introduction of this paper, different advances have been presented. Firstly when it comes to the nature of the austenitisation reaction under superheating conditions (extreme thermal kinetics), the stress-free dilatometry results have shown that the start and end temperatures of the austenite transformation (Ac1 and Ac3) are always dependent on the heating rate. In the same way, the austenisation range varies continuously even for higher values $\left(11,000^{\circ} \mathrm{C} / \mathrm{s}\right)$. So, the time-dependent nature of the transformation appears over the whole heating rate range tested. The continuity of the austenite transformation diffusional nature can be put forward. So in the case of AISI S15500 superheating, the assumption of Leem et al. (2001), Kappoor and Batra (2004) on a possible displacive nature of the austenitisation transformation is not validated.

Consequently, Leblond model, adapted to the simulation of anisothermal time-dependent transformations, seems to be suitable to reproduce the measured transformation kinetics.

Secondly, it is important to note that, for a heating rate higher than $1,300^{\circ} \mathrm{C} / \mathrm{s}$, all the model parameters $\left(Z_{e q}, \tau, \ldots\right)$ become independent from $|\dot{T}|$.. Since the identification leads to a stabilisation of parameters, the evolution of the austenisation rate only depends on the model reaction [equation (2)] to thermal kinetic variations. Therefore, the extrapolation to higher thermal kinetics is justified. So for AISI S15500 , the minimum heating rate for the calibration of a transformation model is around $1,300^{\circ} \mathrm{C} / \mathrm{s}$ (= stabilisation temperature of all parameters). This minimum heating rate $\left(1,300^{\circ} \mathrm{C} / \mathrm{s}\right.$ ) is clearly higher than the heating rates currently used $\left[50^{\circ} \mathrm{C} / \mathrm{s}\right.$ for Brosse $(2009), 80^{\circ} \mathrm{C} / \mathrm{s}$ for Zavala (2005)].

Finally, the importance of considering the temporal aspect in the metallurgical model clearly appears when coupling the calibrated austenitisation model of AISI S15500 with the thermal cycle of a classical turning operation (extracted from a machining numerical model).

Indeed, with a metallurgical model (Chou and Song, 2005 or Umbrello and Filice, 2009) considering only a transformation start temperature and two levels of austenite proportion $(0 \%$ or $100 \%)$, the thermal cycle studied would have resulted in complete austenitisation (the maximal temperature reached during machining is clearly higher than the Ac1 temperature). With the calibrated model, the percentage of austenite formed is less than $0.4 \%$ after the tool passing (heating and cooling phase). This is due to the 
consideration of the austenitisation kinetics in the metallurgical model and its calibration with high heating rates.

\section{Conclusions}

Finally, this study presents a methodology to calibrate a metallurgical model adapted to the thermal kinetics of a turning operation. Stress-free dilatometry tests have been performed to measure the kinetics of the austenite transformation for an AISI S15500 martensitic stainless steel. Very high heating rates have been applied (from $6^{\circ} \mathrm{C} / \mathrm{s}$ to $11,000^{\circ} \mathrm{C} / \mathrm{s}$ ) in order to approach the thermal cycles characterising the machining of metallic parts. Using the experimental data of the stress-free dilatometry tests, the parameters of Leblond metallurgical model have been calibrated.

This metallurgical transformation model makes it possible to test different heating rate, cooling rate and maximum temperature combinations. So a typical thermal cycle (heating and cooling) for a turning operation has been chosen and applied. It shows that the proportion of austenite produced is near zero if the heating and cooling rates are very high (more than $10^{6 \circ} \mathrm{C} / \mathrm{s}$ ). This highlights the importance of calibrating the metallurgical transformation models at high heating rates (more than $1,300^{\circ} \mathrm{C} / \mathrm{s}$ for AISI S15500 steel ) and not only considering an austenitisation start temperature. The temporal aspect cannot be neglected in austenitisation models.

It is important to note that this study only deals with the thermal energy involved in the microstructure transformation. The influence of high levels of deformation and stress on the transformation kinetics is not taken into account. However it is the context usually encountered during the manufacture of metallic parts. The influence of deformation and stress levels on phase change temperatures should be investigated. This point clearly represents the direct continuation of this study. Moreover, the calibrated metallurgical model can be directly implemented in the machining model of residual stress prediction. In this way, it will be a complete model of surface integrity prediction.

\section{Acknowledgements}

The authors would like to express their gratitude to the EUROCOPTER Company, AREVA NP Company and the CETIM Company for their financial support.

\section{References}

Aramcharoen, A. and Mativenga, P.T. (2008) 'White layer formation and hardening effects in hard turning of $\mathrm{H} 13$ tool steel with CrTiAlN and CrTiAlN/MoST-coated carbide tools', International Journal of Advanced Manufacturing Technology, Vol. 36, Nos. 7-8, pp.650-657.

Bissey-Breton, S., Farré, J., Vignal, V. and Mary, N. (2007) 'Impact des conditions d'usinage sur la zone du matériau affectée par le procédé’, Mécanique et Industries, Vol. 8, No. 3, pp.193-197.

Brosse, A. (2009) Modélisation expérimentale et numérique des effets induits par la rectification. Application à la rectification haute productivité, $\mathrm{PhD}$ thesis, École Nationale Supérieure des Mines de Saint-Étienne, France. 
Burns, T.J., Mates, S.P., Rhorer, R.L., Whitenton, E.P. and Basak, D. (2009) 'Dynamic properties for modeling and simulation of machining: an update of results from the NIST pulse-heated Kolsky bar', Proceedings of the 12th CIRP Conference on Modelling of Machining Operations, San Sebastian, Spain, 7-8 May, pp.255-262.

Chou, Y.K. (2002) 'Surface hardening of AISI 4340 steel by machining: a preliminary investigation', Journal of Materials Processing Technology, Vol. 124, Nos. 1-2, pp.171-177.

Chou, Y.K. and Evans, C.J. (1999) 'White layers and thermal modeling of hard-turned surfaces', International Journal of Machine Tools and Manufacture, Vol. 39, No. 12, pp.1863-1868.

Chou, Y.K. and Song, H. (2005) 'Thermal modeling for white layer predictions in finish hard turning', International Journal of Machine Tools and Manufacture, Vol. 45, Nos. 4-5, pp.481-495.

Constant, A., Henry, G. and Charbonnier, J.C. (1992) Principes de base des traitements thermiques, thermomécaniques et thermochimiques des aciers, PYC édition, Ivry-sur-Seine, France, ISBN: 2-85330-110-9.

Davim, J.P. (2008) Machining: Fundamentals and Recent Advances, Springer-Verlag, London.

Fernández-Abia, A.I., Barreiro, J., López de Lacalle, L.N. and Martínez-Pellitero, S. (2012) 'Behavior of austenitic stainless steels at high speed turning using specific force coefficients', The International Journal of Advanced Manufacturing Technology, Vol. 62, Nos. 5-8, pp.505-515.

Herny, E., Lours, P., Andrieu, E., Cloue, J.M. and Lagain, P. (2008) 'Evolution of microstructure and impact-strength energy in thermally and thermomechanically aged 15-5 PH', Proceedings of the Institution of Mechanical Engineers, Part L: Journal of Materials: Design and Applications, Vol. 222, pp.299-304.

Jawahir, I.S., Brinksmeier, E., M’Saoubi, R., Aspinwall, D.K., Outeiro, J.C., Meyer, D., Umbrello, D. and Jayal, A.D. (2011) 'Surface integrity in material removal processes: recent advances’, CIRP Annals - Manufacturing Technology, Vol. 60, No. 2, pp.603-626.

Kappoor, R. and Batra, I.S. (2004) 'On the $\alpha$ ' to $\gamma$ transformation in maraging (grade 350), PH 13-8 Mo and 17-4 PH steels', Materials Science and Engineering, Vol. 371, Nos. 1-2, pp.324-334.

Katsamas, A.I. (2007) 'A computional study of austenite formation kinetics in rapidly heated steels’, Surface and Coatings Technology, Vol. 201, No. 14, pp.6414-6422.

Koistinen, D.P. and Marburger, R.E. (1959) 'A general equation prescribing extent of austenite-martensite transformation in pure Fe-C alloys and plain carbon steels', ActaMetallurgica et Materialia, Vol. 7, No. 1, pp.59-60.

Krauss, G. (1990) Steels: Heat Treatment and Processing Principles, 2nd edition, ASM International, Novelty, ISBN-10: 087170370X.

Leblond, J.B. and Devaux, J. (1984) 'A new kinetic model for anisothermal metallurgical transformations in steel including effect of austenite grain size', Acta Metallurgica et Materialia, Vol. 32, No. 1, pp.137-146.

Leblond, J.B., Mottet, G. and Devaux, J.C. (1986) 'A theoretical and numerical approach to the plastic behavior of steels during phase transformations. I: derivation of general relations', Journal of the Mechanics and Physics of Solids, Vol. 34, No. 4, pp.395-409.

Lee, S.J. and Lee, Y.K. (2008) 'Finite element simulation of quench distortion in a low-alloy steel incorporating transformation kinetics’, Acta Materialia, Vol. 56, No. 7, pp.1482-1490.

Leem, D.S., Jun, J.H. and Choi C.S. (2001) 'Amount of retained austenite at room temperature after reverse transformation of martensite to austenite in an $\mathrm{Fe}-13 \% \mathrm{Cr}-7 \% \mathrm{Ni}-3 \% \mathrm{Si}$ martensitic stainless steel', Scripta Materialia, Vol. 45, No. 7, pp.767-772.

Liu, C.R. and Yang, X. (2001) 'The scatter of surface residual stresses produced by face-turning and grinding', Machining Science and Technology, Vol. 5, No. 1, pp.1-21.

Mioković, T., Schulze,V., Vöhringer, O. and Löhe, D. (2006) 'Prediction of phase transformations during laser surface hardening of AISI 4140 including the effects of inhomogeneous austenite formation', Materials Science and Engineering: A, Vols. 435-436, No. 5, pp.547-555. 
Mioković, T., Schulze,V., Vöhringer, O. and Löhe, D. (2007) 'Influence of cyclic temperature changes on the microstructure of AISI 4140 after laser surface hardening', Acta Materialia, Vol. 55, pp.589-599.

Mondelin, A., Valiorgue, F., Rech, J., Coret, M. and Feulvarch, E. (2011) '3D numerical prediction of residual stresses in turning of 15-5PH', Advanced Materials Research, Vol. 223, pp.411-420.

Mondelin, A., Valiorgue, F., Rech, J., Coret, M. and Feulvarch, E. (2012) 'Hybrid model for the prediction of residual stresses induced by AISI S15500 steel turning', International Journal of Mechanical Sciences, Vol. 58, No. 1, pp.69-85.

Orlich, J., Rose, A. and Wiest, P. (1973) Atlas zürWarmebehandlung der Stähle. Zeit Temperatur Austenitisierung Schaubilder, MPI, Berlin.

Outeiro, J.C., Pina, J.C., M’Saoubi, R., Pusavec, F. and Jawahir, I.S. (2008) 'Analysis of residual stresses induced by dry turning of difficult-to-machine materials', CIRP Annals Manufacturing Technology, Vol. 57, No. 1, pp.77-80.

Patwa, R. and Shin, Y.C. (2007) 'Predictive modeling of laser hardening of AISI5150H steels', International Journal of Machine Tools and Manufacture, Vol. 47, No. 2, pp.307-320.

Poulachon, G. (1999) Aspects phénoménologiques, mécaniques et métallurgiques en tournage c-BN des aciers durcis. Application : usinabilité de l'acier 100Cr6, $\mathrm{PhD}$ thesis, Arts et Métiers Cluny, France.

Ramesh, A. and Melkote, S.N. (2008) 'Modeling of white layer formation under thermally dominant conditions in orthogonal machining of hardened AISI 52100 steel', International Journal of Machine Tools and Manufacture, Vol. 48, Nos. 3-4, pp.402-414.

Rech, J., Hamdi, H. and Valette, S. (2008) 'Workpiece Surface Integrity’, in Davim, J.P. (Ed.): Machining: Fundamentals and Recent Advances, Springer-Verlag, London.

Reti, T., Bagyinszki, G., Felde, I., Ver, B. and Bell, T. (1999) 'Prediction of as-quenched hardness after rapid austenitization and cooling of surface hardened steels', Computational Materials Science, Vol. 15, No. 1, pp.101-112.

Smith, S., Melkote, S.N., Lara-Curzio, E., Watkins, T.R., Allard, L. and Riester, L. (2007) 'Effect of surface integrity of hard turned AISI 52100 steel on fatigue performance', Materials Science and Engineering: A, Vol. 459, Nos. 1-2, pp.337-346.

Umbrello, D. (2011) 'Influence of material microstructure changes on surface integrity in hard machining of AISI 52100 steel', International Journal of Advanced Manufacturing Technology, Vol. 54, Nos. 9-12, pp.887-898.

Umbrello, D. and Filice, L. (2009) 'Improving surface integrity in orthogonal machining of hardened AISI 52100 steel by modeling white and dark layers formation', CIRP Annals Manufacturing Technology, Vol. 58, No. 1, pp.73-76.

Valiorgue, F., Rech, J., Hamdi, H., Gilles, P. and Bergheau, J.M. (2012) '3D modeling of residual stresses induced in finish turning of an AISI304L stainless steel', International Journal of Machine Tools and Manufacture, Vol. 53, No. 1, pp.77-90.

Wu, T. (2007) Experiment and Numerical Simulation of Welding Induced Damage Stainless Steel AISI S15500, PhD thesis, University of Lyon, France.

Yang, X., Liu, C.R. and Grandt, A.F. (2002) 'An experimental study on fatigue life variance, residual stress variance, and their correlation of face-turned and ground Ti 6Al-4V samples', Journal of Manufacturing Science and Engineering, Vol. 124, No. 4, pp.809-819.

Zavala, I. (2005) Prédiction des distorsions dans le cas du soudage TIG de l'acier 17-4PH; Elaboration d'un modèle avec prise en compte des phénomènes de durcissement par precipitation, $\mathrm{PhD}$ thesis, Université de Bretagne Sud, France. 